\title{
Optical and electrochemical properties of tunable host-guest complexes linked to plasmonic interfaces $\uparrow$
}

\author{
Fatiha Barka-Bouaifel, ${ }^{a b}$ Joanna Niedziółka-Jönsson, ${ }^{a}$ Xavier Castel, ${ }^{c}$ Ophélie Saison, ${ }^{d}$ Abdellatif Akjouj, ${ }^{d}$ \\ Yan Pennec, ${ }^{d}$ Bahram Djafari-Rouhani, ${ }^{d}$ Patrice Woisel, ${ }^{* e}$ Joël Lyskawa, ${ }^{e}$ Léna Sambe, ${ }^{e}$ Graeme Cooke, ${ }^{f}$ \\ Nacer Bezzi, ${ }^{b}$ Rabah Boukherroub ${ }^{a d}$ and Sabine Szunerits *ad
}

This article describes the use of localized surface plasmon resonance (LSPR) interface to detect complexation/decomplexation steps of a controllable host-guest system at the solid-liquid interface. The LSPR interfaces consist of a sandwiched structure comprising a tin-doped indium oxide (ITO) substrate, gold nanostructures (Au NSs) and a thin ITO film overcoating. "Click" chemistry was used to covalently link an alkyne-functionalized $\pi$-electron deficient tetracationic cyclophane cyclobis(paraquat- $p$-phenylene) (CBPQT ${ }^{4+}$ ) unit to an azide-terminated LSPR interface. The modified interfaces were characterized using X-ray photoelectron spectroscopy (XPS), cyclic voltammetry and UV-vis transmission spectroscopy. Tetrathiafulvalene (TTF) was used as a model guest molecule to demonstrate the possibility to follow the complexation/decomplexation events by monitoring the change in the LSPR signal. The results demonstrate that redox controlled host-guest complexation at the surface can be monitored effectively using LSPR.

\section{Introduction}

The properties of non-covalently associated systems such as pseudorotaxanes and interlocked systems such as rotaxanes and catenanes have shown considerable promise for the construction of sensors and devices, due to their ability to respond to a range of external stimuli. ${ }^{1-4}$ One of the most widely studied host

anstitut de Recherche Interdisciplinaire (IRI, USR-3078), Université de Lille1, Parc de la Haute Borne, 50 avenue de Halley, BP 70478, 59658 Villeneuve d'Ascq, France. E-mail: sabine.szunerits@iri.univ-lille1.fr; Fax: +33 3625317 01; Tel: +33362531724

${ }^{b}$ Laboratoire de Technologie des Matériaux et de Génie des Procédés (LTMGP), Université Abderrahmane Mira de Bejaia, Targa Ouzemour, 06000 Béjaia, Algeria

'Institut d'Electronique et de Télécommunications de Rennes (IETR-UMR CNRS 6164), 18 rue Henri Wallon, PB 406, 22004 Saint-Brieuc, Cedex 1, France

'Institut d'Electronique, de Microélectronique et de Nanotechnologie (IEMN), UMR-CNRS 8520, Université de Lille 1, Cité Scientifique, 59655 Villeneuve d'Ascq, France

${ }^{e}$ Unité Matériaux et Transformations (UMET, CNRS-8207), Equipe Ingénierie des Systèmes Polymères, Université des Sciences et Technologies de Lille, 59655 Villeneuve d'Ascq, France. E-mail: patrice. woidel@ensc-lille.fr; Fax: +33 3204343 45; Tel: +33 320434954

${ }^{f}$ GCPOC, WestCHEM, School of Chemistry, College of Science and Engineering, University of Glasgow, G12 8QQ, UK

$\uparrow$ Electronic supplementary information (ESI) available: Cyclic voltammograms of ITO electrode in $\mathrm{Fe}(\mathrm{CN})_{6}{ }^{4-}$ and $\mathrm{CBPQT}^{4+}$ as well as cyclophane-modified ITO; UV/Vis spectra of alkynyl-functionalized $\mathrm{CBPQT}^{4+}$, TTF and the TTF-CBPQT ${ }^{4+}$ guest-host complex. See DOI: $10.1039 / \mathrm{c} 0 \mathrm{jm} 03293 \mathrm{j}$ systems is the $\pi$-electron deficient tetracationic cyclophane cyclobis(paraquat- $p$-phenylene) $\left(\mathrm{CBPQT}^{4+}\right)$, which readily forms redox-controllable host-guest systems with $\pi$-electron rich molecules such as tetrathiafulvalene (TTF) and 1,5-dioxynaphthalene derivatives. ${ }^{5}$ Although these systems have been extensively studied in solution phase using a range of analytical techniques, for device orientated applications, it is desirable that these systems are immobilized onto a surface. ${ }^{6}$ An early report on linking interlocked supramolecular systems of this type onto a gold surface was based on complexes formed between $\mathrm{CBPQT}^{4+}$ and bis-thiol functionalised thread featuring a 1,4dialkyloxy phenyl unit. ${ }^{7,8}$ More recently, more elaborate systems have been developed using silane ${ }^{9,10}$ or gold-sulfur based selfassembled monolayers (SAMS) ${ }^{11-15}$ and electropolymerization techniques $^{16-19}$ to deposit CBPQT ${ }^{4+}$ host-guest systems onto surfaces. ${ }^{6,16,20,21}$ An important consideration in designing surfaces functionalized with supramolecules is that the behavior of the anchored systems remains the same after surface attachment.

"Click" chemistry, a generic term describing a range of chemical transformations characterized by high efficiency, selectivity and tolerance to a variety of solvents and functional groups, has proved to be a useful method to link supramolecular systems to solid substrates. ${ }^{22}$ The concept was introduced by Sharpless et $\mathrm{al}^{23}$ and is usually based on the copper(I) catalyzed triazole formation through the classic Huisgen 1,3-dipolar cycloaddition between azides and alkynes. The appealing characteristics of the azide-alkyne click reactions have led to its rapid 
utilisation in a range of chemistry applications including organic, medicinal, polymer and materials chemistry. "Click" chemistry has been indeed used to synthesize interlocked supramolecular structures such as rotaxanes and catenanes in solution. ${ }^{24-26}$ However, to the best of our knowledge, this approach has not until now been used to surface-link CBPQT ${ }^{4+}$ units to ITO based surfaces.

Here, we report on the use of "click" chemistry to anchor alkyne-functionalized $\mathrm{CBPQT}^{4+}$ to plasmonic interfaces. We have subsequently exploited the presence of the $\mathrm{CBPQT}^{4+}$ unit to specifically and reversibly modulate, under redox control, the plasmonic response using host-guest interactions with a TTF unit. The position of the LSPR band $\left(\lambda_{\max }\right)$ is sensitive to changes in the environment around the metallic nanostructures, allowing easy and rapid detection of interfacial interactions and modifications. ${ }^{27-29}$ The interface used in this study is based on a multilayer architecture (Fig. 1) developed in our group. ${ }^{30}$ It consists of gold nanostructures ( $\mathrm{Au} \mathrm{NSs}$ ) deposited onto an indium tin oxide (ITO) substrate and coated with an ITO overlayer of different thicknesses. Indeed, one of the initial problems for accurate LSPR sensing was the poor adhesion of metallic nanostructures to the underlying surface, leading to morphological changes upon exposure to solvents and analytes. ${ }^{31,32}$ The use of multilayered LSPR interfaces permits a good chemical protection of the plasmonic interface. ${ }^{30,33-42}$ In addition, it widens the surface functionalization schemes for the coupling of organic and/or biological molecules. ${ }^{33,34,36,39}$ The hydroxyl groups of the ITO overcoating are used here to form azide-terminated LSPR interfaces onto which alkyne-functionalized $\mathrm{CBPQT}^{4+}$ can be easily linked.

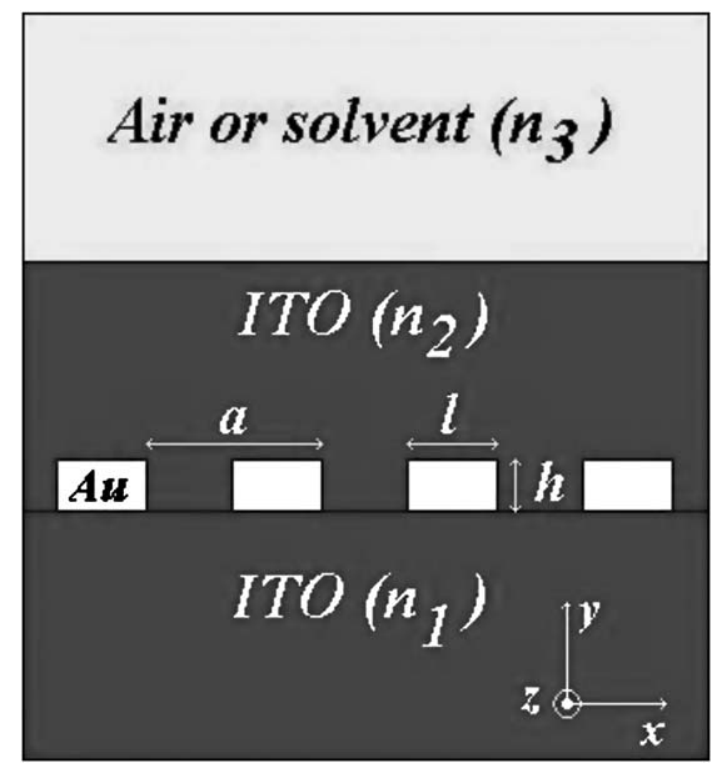

Fig. 1 Schematic representation of the structure studied in this work. The gold nanorod is characterized by the height $h$ and the width $l$. The lattice parameter " $a$ " is defined as the distance between two nearest neighboring gold nanorods. The input source is placed in the substrate and the detector in air or solvent.

\section{Experimental section}

\subsection{Materials}

ITO (sheet resistivity $15-25 \quad \Omega \quad \mathrm{sq}^{-1}$ ), potassium hexacyanoferrate(II) $\left[\mathrm{K}_{4} \mathrm{Fe}(\mathrm{CN})_{6}\right]$, potassium chloride $(\mathrm{KCl}), N, N$ dicyclohexylcarbodiimide (DCC), 4-dimethylaminopryridine (DMAP), methanol, ethanol, copper iodide (CuI), dichloromethane $\left(\mathrm{CH}_{2} \mathrm{Cl}_{2}\right)$, dimethyl formamide (DMF), tetrabutylammonium hexafluorophosphate $\left(\mathrm{TBAPF}_{6}\right)$, iron perchlorate $\left[\mathrm{Fe}\left(\mathrm{ClO}_{4}\right)_{3}\right]$, 8-diazabicyclo[5.4.0]undec-7-ene (DBU), acetonitrile, 1,3-propanediol and carbon disulfide $\left(\mathrm{CS}_{2}\right)$ were purchased from Sigma-Aldrich. 4-Azidobenzoic acid was obtained from TCI Europe. 3-Aminopropyltrimethoxysilane (APTMS) was obtained from Gelest.

\subsection{Preparation of LSPR interfaces: ITO/Au NSs/ITO}

2.2.1. ITO/Au NSs. ITO slides $\left(76 \times 26 \times 1 \mathrm{~mm}^{3}\right)$ were cleaned with acetone and isopropanol, rinsed with Milli-Q water and dried under a nitrogen stream. A $2 \mathrm{~nm}$ thin gold film was deposited by thermal evaporation $\left(0.1 \AA^{-1} \mathrm{~s}^{-1}\right)$ at a base pressure of $10^{-7}$ to $10^{-8}$ Torr using a MECA 2000-1 system (Plassys) with about $10 \%$ accuracy. Post-deposition annealing of the gold film was performed under nitrogen stream at $500{ }^{\circ} \mathrm{C}$ for $1 \mathrm{~min}$ using a rapid thermal annealer (Jipelec Jet First 100).

2.2.2. Deposition of ITO overlayers. ITO overcoatings were deposited on the ITO/Au NSs interface using r.f. sputtering (Plassys MP 450S) at $8.10^{-8} \mathrm{mbar}$ (turbomolecular rotary pump system). ${ }^{30,43,44}$ The deposition chamber contains an $\mathrm{In}_{2} \mathrm{O}_{3}-\mathrm{SnO}_{2}$ $\left(\mathrm{In}_{2} \mathrm{O}_{3} \quad 90 \% \mathrm{w} / \mathrm{w}\right) ; \mathrm{SnO}_{2} \quad 10 \% \mathrm{w} / \mathrm{w} 99.999 \%$ purity) ceramic sputtering target ( $75 \mathrm{~mm}$ in diameter). The deposition temperature is measured with a thermocouple set behind the sample holder. ITO deposition is carried out at a r.f. power of 13.56 $\mathrm{MHz}$ under oxygen/argon atmosphere using the following parameters: r.f. power $=38 \mathrm{~W}$, total pressure $=0.012 \mathrm{mbar}, \mathrm{O}_{2} /$ Ar ratio $=0.051$, deposition rate $=0.6 \mathrm{~nm} \mathrm{~min}^{-1}$, and substrate temperature $=25^{\circ} \mathrm{C}$.

\subsection{Surface functionalization}

2.3.1. Silanization with APTMS. A low pressure mercury arc lamp (UVO cleaner, Nr. 42-220, Jelight, USA, $P=1.6 \mathrm{~mW} \mathrm{~cm}$, distance from sample: $3 \mathrm{~mm}$ ) was used to generate surface hydroxyl groups on the ITO/Au NSs/ITO hybrid interfaces. Amine-terminated ITO/Au NSs/ITO hybrid interfaces were prepared by chemical treatment of the clean surface with $3 \%$ 3-aminopropyltrimethoxysilane (APTMS) in methanol/water (v/ v: $95 / 5)$ for 30 minutes under sonication. The interfaces were then washed with methanol, water (two times), methanol and annealed for $20 \mathrm{~min}$ at $110{ }^{\circ} \mathrm{C} .{ }^{45}$

2.3.2. Azide termination. 4-Azidobenzoic acid ( $2 \mathrm{mmol})$, $N, N$-dicyclohexylcarbodiimide $(2.2 \mathrm{mmol})$ and 4-dimethylaminopryridine (DMAP, $0.66 \mathrm{mmol}$ ) were dissolved in dry dichloromethane $(20 \mathrm{~mL})$. The amine-terminated ITO/Au NSs/ ITO hybrid interfaces were immersed in the solution and left at room temperature for $24 \mathrm{~h}$ under nitrogen atmosphere. The samples were then washed with dichloromethane $(5 \mathrm{~min}, 2$ 
times), ethanol (5 min, 2 times) and finally with water, and dried under a nitrogen stream. ${ }^{30}$

2.3.3. "Clicking" alkyne-functionalized cyclophane (1) to azide-terminated surface. The azide-terminated ITO/Au NSs/ITO surface was immersed in $10 \mathrm{~mL}$ of a solution of acetonitrile with alkyne-functionalized cyclophane $(2 \mathrm{mM}), \mathrm{CuI}(2 \mathrm{mM})$ and $\mathrm{DBU}(0.1 \mathrm{M})$ and kept for $48 \mathrm{~h}$ at $70{ }^{\circ} \mathrm{C}$. The resulting surface was washed with acetonitrile, ethanol and water, and dried under a stream of nitrogen. ${ }^{30}$

\subsection{Instrumentation}

2.4.1. X-Ray photoelectron spectroscopy. X-Ray photoelectron spectroscopy (XPS) measurements were performed with an ESCALAB $220 \mathrm{XL}$ spectrometer from vacuum Generators. A monochromatic $\mathrm{Al} \mathrm{K} \alpha \mathrm{X}$-ray source $(1486.6 \mathrm{eV})$ was operated in the CAE (constant analyzer energy) mode (CAE $=100 \mathrm{eV}$ for survey spectra and $\mathrm{CAE}=40 \mathrm{eV}$ for high-resolution spectra), using the electromagnetic lens mode. No flood gun source was needed due to the conducting character of the substrates. The angle between the incident X-rays and the analyzer is $58^{\circ}$. The detection angle of the photoelectrons is $90^{\circ}$, as referenced to the sample surface.

2.4.2. Contact angle measurements. Water contact angles were measured using deionized water. We used a remotecomputer controlled goniometer system (DIGIDROP by GBX, France) for measuring the contact angles. The accuracy is $\pm 2^{\circ}$. All measurements were made in ambient atmosphere at room temperature.

2.4.3. Electrochemical measurements. Cyclic voltammetry (CV) was performed with an Autolab potentiostat 30 (EcoChemie, Utrecht, The Netherlands). A platinum mesh and a silver wire were used as a counter and a reference electrode, respectively. The scan rate was $50 \mathrm{mV} \mathrm{s}^{-1}$ and the active surface area was $0.04 \mathrm{~cm}^{2}$.

2.4.4. UV/vis spectrometry. Absorption spectra were recorded using a PerkinElmer Lambda UV/Vis 950 spectrophotometer in polystyrene cuvettes with an optical path of $10 \mathrm{~mm}$. The wavelength range was $400-800 \mathrm{~nm}$.

2.4.5. Simulation method. Calculations are performed using a Finite Difference Time Domain (FDTD) method, which solves the Maxwell's equations by discretizing both time and space and by replacing derivatives with finite differences. ${ }^{46,47}$ Our calculation is performed in a two-dimensional (2-D) box (along $x$ and $y$ axes, see Fig. 1) with a propagation along the $y$ axis. Perfect Matching Layer (PML) conditions are applied at the boundaries $y$ of the box, in order to avoid reflections of outgoing waves. ${ }^{48}$ Along the $x$ direction, the unit cell is repeated periodically and the structure is supposed to be infinite along the $z$ direction. Space is discretized in both $x$ and $y$ directions using a mesh interval equal to $\Delta x=\Delta y=1 \mathrm{~nm}$. The equations of motion are solved with a time integration step $\Delta t=\Delta x /(4 c)$, where $c$ is the velocity of the light in vacuum and the number of time steps equals to $2,{ }^{20}$ which is the necessary tested time for a good convergence of the numerical calculation.

The incoming pulse, having TM polarization, is generated at the bottom part of the unit cell by a current source parallel to the $x$ axis and having a planar profile along the $x$ direction. The current is generated during a short period of time in such a way as to excite the electromagnetic waves in the frequency domain of interest. The transmitted signal, probed at the end of the upper part of the unit cell, is recorded as a function of time and finally Fourier transformed to obtain the transmission coefficient versus frequency.

\section{Results and discussion}

\subsection{Theoretical considerations}

To use the optimal LSPR interface in terms of refractive index sensitivity, theoretical calculations were performed on ITO/Au NSs interfaces coated with differently thick ITO overlayers. The Lorentz and Drude model was used to investigate the optical behavior of ITO/Au NSs/ITO substrates based on the interface configuration in Fig. $1 .^{35}$ It consists of a layer of gold nanostructures of diameter $l$, height $h$ and interparticle distance $a$ deposited on ITO (refractive index $n_{1}=2.00$ ), coated with a dielectric of the same refractive index $n_{2}=2.00$. This interface is furthermore covered by a non-absorbing medium of refractive index $n_{3}$ such as air, water, 1,3-propanediol and carbon disulfide. For the calculations, the following geometrical parameters were chosen: $l=25 \mathrm{~nm}, h=15 \mathrm{~nm}, a=70 \mathrm{~nm}$. This corresponds to an average metal coating of $37 \%$. Fig. 2A shows the theoretical change in $\lambda_{\max }$ as a function of the thickness of the ITO coating layer when immersed in solvents of increasing refractive index. At short distances from the nanoparticles surface, the LSPR shift follows a steep slope with a change in $\lambda_{\max }$ by about $60 \mathrm{~nm}$. As the distance from the nanoparticles increases, the curve bends over and shows a subsequent blue shift, followed by another sharp red-shift. The periodicity of the oscillation can be calculated by the equation: $d_{\mathrm{p}}=\lambda_{\max } /\left(2 n_{2}\right)$, where $n_{2}$ is the refractive index of the dielectric layer $\left[d_{\mathrm{p}}(\mathrm{ITO})=640 /(2 \times 2)=160 \mathrm{~nm}\right]$. The periodicity of the oscillation is independent of the solvent used (i.e., independent of the refractive index $n_{3}$ ). However, the amplitude of the oscillation is strongly affected by the value of the refractive index $n_{3}$ of the solvent.

Fig. 2B shows in the form of a bare diagram the evolution of the sensitivity $S$ in nm RIU ${ }^{-1}$ (change of nanometre per refractive index unit) as a function of the ITO layer thickness. The sensitivity decreases with the deposition of ITO overlayers. For $d_{\text {ITO }}$ $\leq 20 \mathrm{~nm}$, the calculated sensitivities are comparable to uncoated ITO/Au NSs interfaces. Negative sensitivities are observed for interfaces coated with $40-80 \mathrm{~nm}$ and 180-240 nm. We observed that the sensitivity becomes zero for $d_{\text {ITO }} \approx 90,165$ and $250 \mathrm{~nm}$. The sensitivities of the ITO/Au NSs/ITO interface architectures were compared with results on glass/Au NSs/glass and glass/Au NSs/ITO interfaces as reported previously. ${ }^{49}$ Generally, it can be observed that the sensitivities on ITO/Au NSs are lower than that obtained on glass/Au NSs for thin ITO overcoatings (i.e., $d_{\text {ITO }}$ $\leq 20 \mathrm{~nm}$ ). However, for $d_{\mathrm{ITO}}>30 \mathrm{~nm}$, the sensitivity is more pronounced on ITO/Au NSs than on glass/Au NSs. One can also notice that large negative sensitivities are observed with ITO 
(A)

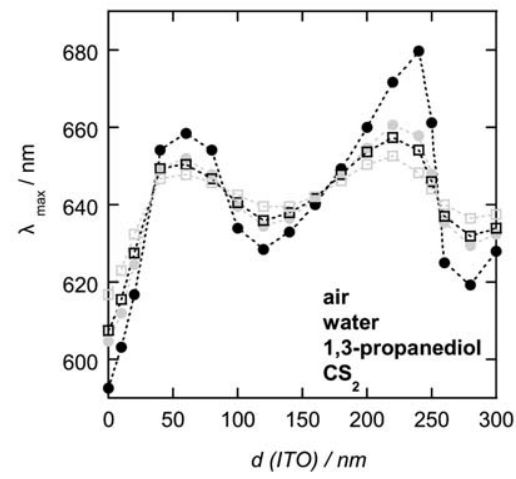

(B)

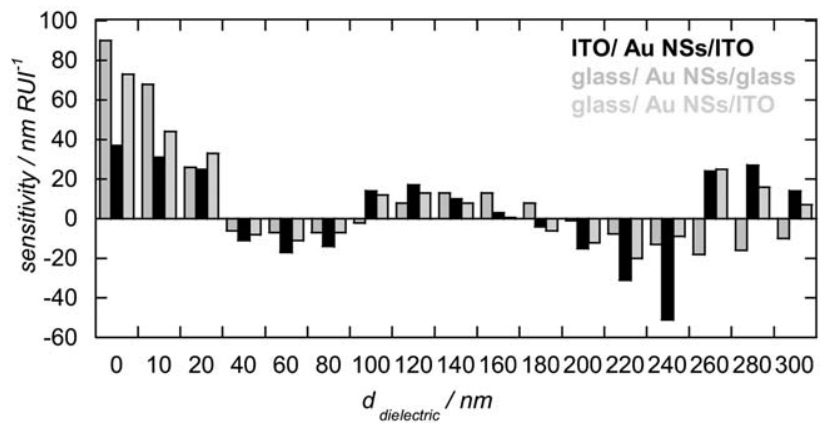

Fig. 2 (A) Theoretically calculated evolution of $\lambda_{\max }$ of an ITO/Au NSs LSPR interface coated with increasingly thick ITO overlayers: air (filled black circles) water (filled grey circles), 1,3-propanediol (open black squares), and $\mathrm{CS}_{2}$ (open grey squares) using $a=70 \mathrm{~nm}, l=25 \mathrm{~nm}, h=15$ $\mathrm{nm}$. (B) Change of refractive index sensitivity for different LSPR interfaces as a function of the top layer thickness: ITO/Au NSs/ITO (black), glass/Au NSs/glass (grey) and glass/Au NSs/ITO (bright grey).

overcoatings as thick as $240 \mathrm{~nm}$. This is rather different to the other cases and shows the complex interplay between the refractive indexes of the overcoating. However, generally the sensitivities obtained are of the same magnitude. In the following, two different ITO overlayer thicknesses were used: 20 and $240 \mathrm{~nm}$.

\subsection{Optical characterization of the ITO/Au NSs/ITO interfaces}

Fig. 3 shows the experimentally obtained UV/vis spectra of ITO/ $\mathrm{Au} \mathrm{NSs}$ and ITO/Au NSs/ITO interfaces in air. The experimentally obtained $\lambda_{\max }$ correlates well with theoretically obtained values (Fig. 2). An additional optical feature next to the main plasmonic peak is seen between 400 and $550 \mathrm{~nm}$, which originates most likely from classical Fabry-Perot cavities due to uncompensated thin film interferences. Indeed, the position of these bands does not change when immersed into different solvents. This behavior is different from that of the main plasmonic peak and the detected maximum wavelength depends on the incident angle of light. The main difference in the LSPR band of the ITO/Au NSs interfaces coated with 20 or $240 \mathrm{~nm}$ thick ITO layers is the peak full width at half maximum (fwhm). For an uncoated ITO/Au NSs interface, the fwhm is $\sim 80 \pm 2 \mathrm{~nm}$, while

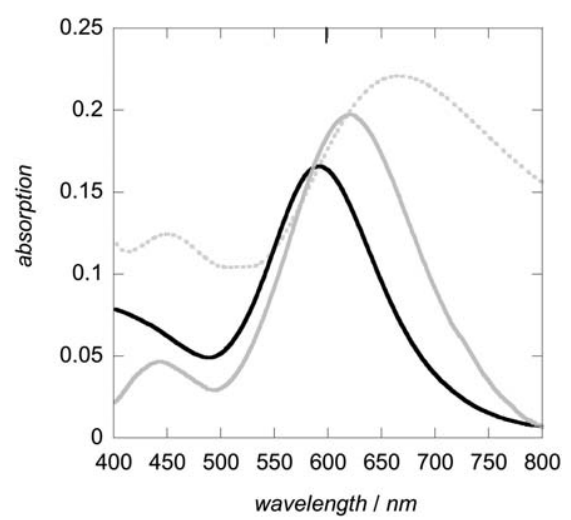

Fig. 3 UV-vis absorption spectra of ITO/Au NSs (black line), ITO/Au NSs/ITO $(20 \mathrm{~nm})$ (grey line) interface and ITO/Au NSs/ITO $(240 \mathrm{~nm})$ (dashed grey line) in air.

its value increased to $\sim 90 \pm 4 \mathrm{~nm}$ for $d_{\text {ITO }}=20$ and $\sim 134 \pm 4 \mathrm{~nm}$ for $d_{\mathrm{ITO}}=240 \mathrm{~nm}$.

\subsection{Linking alkyne-functionalized cylcophane to azide- terminated ITO surface}

Fig. 4 illustrates the surface functionalization strategy employed. A sufficient amount of surface hydroxyl groups was generated on the ITO/Au NSs/ITO LSPR platform by UV/ozone treatment for 10 min. ${ }^{50}$ Amine termination was obtained by silanization of the surface hydroxyl terminal groups with APTMS. Chemical coupling of 4-azidobenzoic acid to the amine-terminated ITO surface resulted in the formation of an azide termination. Finally, the 1,3-dipolar cycloaddition between the azide-terminated surface and 1-alkynyl-cyclophane in the presence of $\mathrm{Cu}(\mathrm{I})$ was used to incorporate cyclophane moieties on the ITO/Au NSs/ITO substrate.

Water contact angle measurements and X-ray photoelectron spectroscopy (XPS) were used to characterize the modified interfaces. The initial ITO/Au NSs/ITO surface exhibits a water contact angle $\theta=30 \pm 2^{\circ}$. This value decreased to $\theta=10 \pm 2^{\circ}$ after photochemical oxidation. Silanization with APTMS resulted in a water contact angle $\theta=40 \pm 2^{\circ}$. Incorporation of the azide function led to an increase of the water contact angle to $\theta=$ $63 \pm 2^{\circ}$. After clicking cyclophane groups to the azide terminal groups, the contact angle dropped to $\theta=55 \pm 2^{\circ}$.

$\mathrm{X}$-Ray photoelectron spectroscopy was used in parallel to evaluate the changes in the surface chemical composition during surface derivatization. Fig. 5 displays the XPS survey spectra of ITO/Au NSs/ITO surfaces before and after silanization with APTMS, coupling of 4-azidobenzoic acid, and clicking cyclophane moieties to the surface. The initial interface shows peaks due to indium at $\sim 17 \mathrm{eV}$ (In 4d), $150 \mathrm{eV}$ (In 4s), $444 \mathrm{eV}$ (In 3d), 665 (In 3p), $703 \mathrm{eV}$ (In 3s), a small contribution due to doping with $\mathrm{Sn}$ at $493 \mathrm{eV}$ (Sn 3d) and a peak at $532 \mathrm{eV}$ due to O 1s. An additional band at $285 \mathrm{eV}$ due to $\mathrm{C} 1 \mathrm{~s}$ from surface contamination is also observed (Fig. 5a). After silanization of the terminal hydroxyl groups with APTMS, a new peak at $\sim 400 \mathrm{eV}$ due to $\mathrm{N}$ $1 \mathrm{~s}\left(-\mathrm{NH}_{2}\right)$ appeared in the XPS survey spectrum (Fig. 5b). From the high resolution XPS of the $\mathrm{N} 1 \mathrm{~s}$, the peak can be deconvoluted into two bands at $399.2 \mathrm{eV}$ due to free amine $\left(-\mathrm{NH}_{2}\right)$ and 


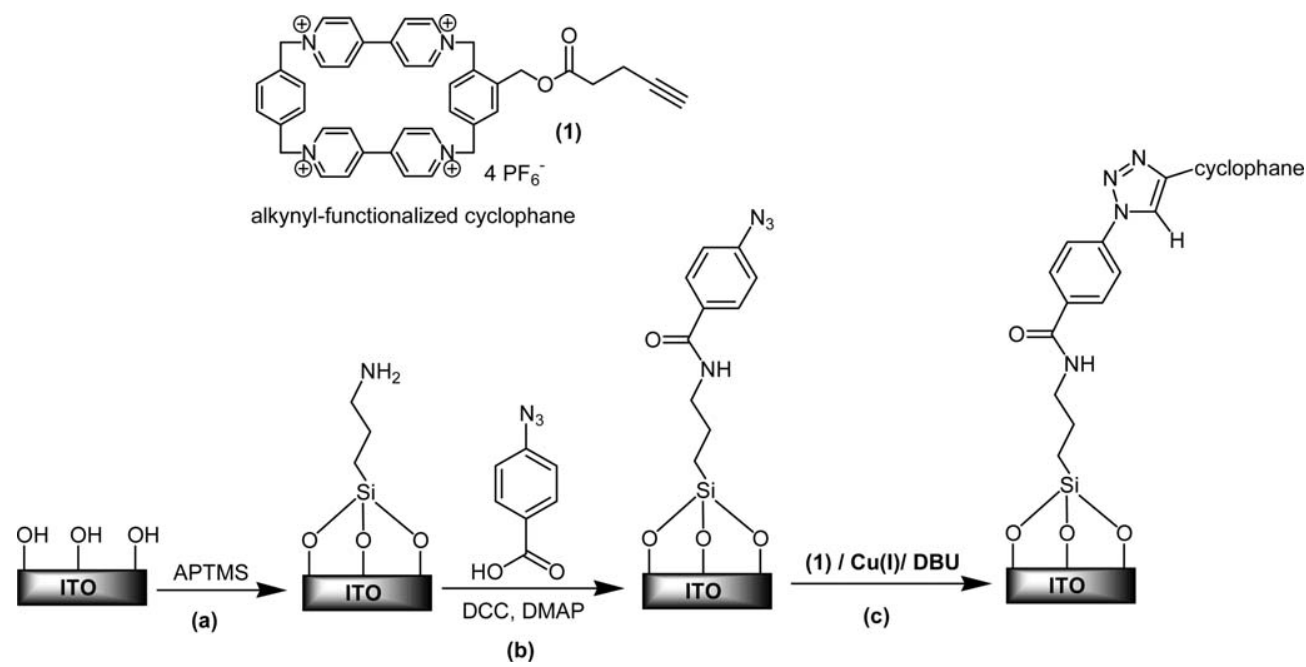

Fig. 4 Schematic illustration of the ITO/Au NSs/ITO surface functionalization with cyclophane moieties. (a) 3\% 3-Aminopropyltrimethoxysilane in $\mathrm{CH}_{3} \mathrm{OH} / \mathrm{H}_{2} \mathrm{O}$ (v/v: 95/5), (b) 4-azidobenzoic acid in dry dichloromethane with addition of $N, N$-dicyclohexylcarbodiimide (DCC) and 4-dimethylaminopryridine (DMAP), (c) alkyne-functionalized cyclophane (1) in acetonitrile with CuI and 8-diazabicyclo[5.4.0]undec-7-ene (DBU).

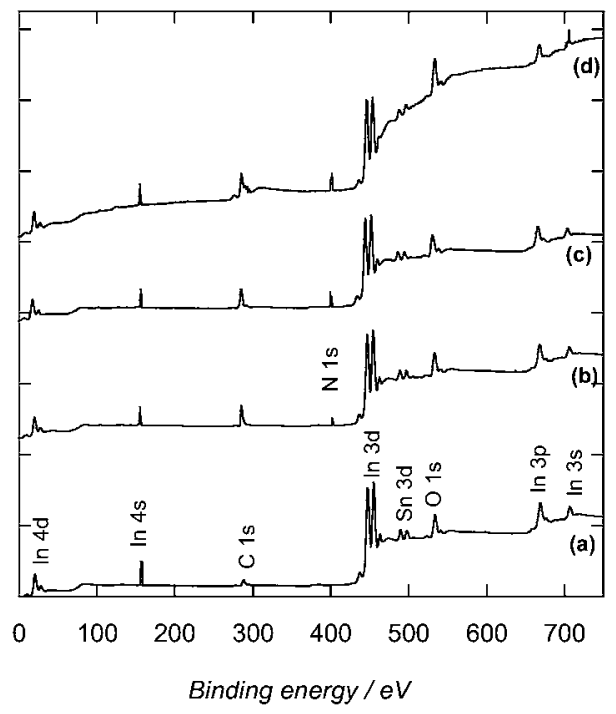

Fig. 5 XPS survey spectra of ITO/Au NSs/ITO interfaces before (a) and after silanization with APTMS (b), incorporating 4-azidobenzoic acid (c), and clicking alkynyl-terminated cyclophane onto an azide-terminated surface $(d)$.

a smaller contribution at 400.6 due to protonated amine groups $\left(-\mathrm{NH}_{3}{ }^{+}\right)$(Fig. 6a).$^{51}$ Covalent coupling of the terminal amine groups with azidobenzoic acid increased the overall nitrogen, carbon and oxygen contents (Fig. 5c). The broad N 1s signal in the high resolution scan was fitted and deconvoluted into three peaks: $400.4 \mathrm{eV}(N=\mathrm{N}=N), 401.2 \mathrm{eV}(-\mathrm{HN}-\mathrm{C}=\mathrm{O})$ and $402.6 \mathrm{eV}$ $(\mathrm{N}=N=\mathrm{N})$ with a ratio of $2.7: 1.3: 1$ close to the expected ratio of $2: 1: 1$ (Fig. 6b).

Upon clicking of 1-alkynyl cyclophane to the azide-terminated interface, the high-resolution $\mathrm{N} 1 \mathrm{~s}$ shows a broad signal centered at $401.7 \mathrm{eV}$, which was fitted and deconvoluted into four peaks: $398.8 \mathrm{eV}(N-\mathrm{N}=\mathrm{N}), 400.3 \mathrm{eV}(\mathrm{N}=\mathrm{N})$ and $400.8 \mathrm{eV}(-\mathrm{HN}-$ $\mathrm{C}=\mathrm{O})$ and $401.7 \mathrm{eV}\left(=\mathrm{N}^{+}\right)$with a ratio of $1: 1.5: 1.7: 4$
(Fig. 6c). This is consistent with the formation of surfaceconfined triazole groups and incorporation of the cyclophane ring. ${ }^{52}$

\subsection{Electrochemical and optical characterizations of the modified ITO/Au NSs/ITO hybrid interfaces}

Cyclic voltammetry using $\mathrm{Fe}(\mathrm{CN})_{6}{ }^{4-}$ as a solution-based redox couple was first performed to evaluate the conductive properties of the modified ITO/Au NSs/ITO interfaces. The ITO/Au NSs/ ITO hybrid interfaces show different behaviors, depending on the ITO overlayer thickness (Fig. 7A). Increasing the ITO overlayer thickness led to an increase of the detected current and electron transfer rate for the oxidation of $\mathrm{Fe}(\mathrm{CN})_{6}{ }_{6}^{4-}$. Indeed, the $20 \mathrm{~nm}$ thick ITO overlayer shows an enlarged $\Delta E_{\mathrm{p}}=200 \pm 15$ $\mathrm{mV}$. This is rather typical for a rough electrode material due to the presence of uncompensated resistance within the ITO overlayer. ${ }^{53} \mathrm{In}$ the case of a $240 \mathrm{~nm}$ thick ITO overlayer, the $i-E$ curve

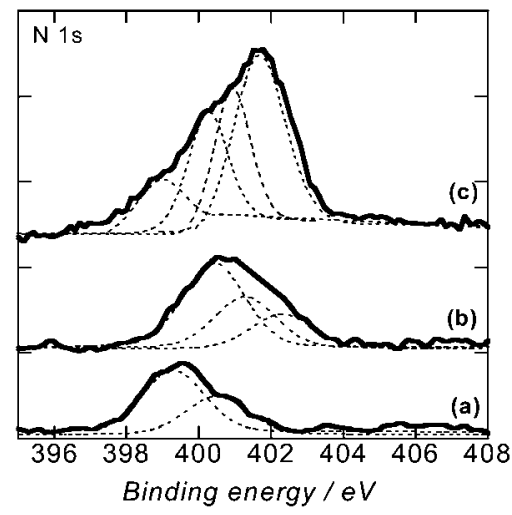

Fig. 6 High-resolution XPS spectra of the N 1s band after silanization with APTMS (a), after incorporating 4-azidobenzoic acid (b), and after "clicking" alkynyl-terminated cyclophane onto an azide-terminated surface (c). 
(A)

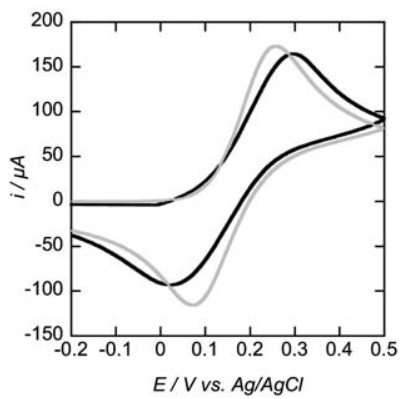

(B)

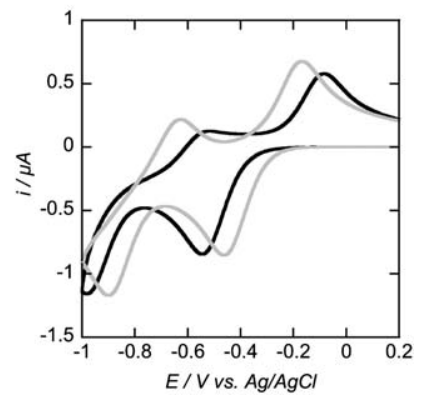

Fig. 7 Cyclic voltammograms of cyclophane-modified ITO/Au NSs/ ITO $(20 \mathrm{~nm})$ (black line) and ITO/Au NSs/ITO (240 nm) (grey line) in (A) an aqueous solution of $10 \mathrm{mM} \mathrm{Fe}(\mathrm{CN})_{6}{ }^{4-} / 0.1 \mathrm{M} \mathrm{KCl}$ and (B) $0.1 \mathrm{M}$ TBAPF $_{6} /$ acetonitrile: $v=50 \mathrm{mV} \mathrm{s}^{-1}, A=0.04 \mathrm{~cm}^{2}$.

is comparable to that of a naked massive bare ITO, where a peak to peak separation $\Delta E_{\mathrm{p}}=180 \pm 15 \mathrm{mV}$ was determined with an apparent electron transfer rate constant $k_{\text {app }} \approx 0.003 \mathrm{~cm} \mathrm{~s}^{-1}$ (see Fig. S1a, ESI†)

Similar behavior was observed when the $\mathrm{CBPQT}^{4+}$-modified LPSR interfaces were immersed into acetonitrile/TBAPF 6 (0.1 M) (Fig. 7B). In the case of a $240 \mathrm{~nm}$ thick ITO, the CV of the surface-bound $\mathrm{CBPQT}^{4+}$ mirrors that obtained for $\mathrm{CBPQT}^{4+}$ on ITO in solution (see ESI, Fig. S1b $†$ ), indicating that its redox properties are not significantly altered by its immobilization onto ITO ${ }^{21}$ Indeed, in the case of a $240 \mathrm{~nm}$ thick ITO overlayer, the $\mathrm{CV}$ gives rise to two-electron quasi-reversible reduction waves at $E^{01}=-0.32 \mathrm{~V}$ and $E^{02}=-0.76 \mathrm{~V}(\mathrm{Ag} / \mathrm{AgCl})$ corresponding to the two step reduction $\left(\mathrm{CBPQT}^{4+} \rightarrow \mathrm{CBPQT}^{2+} \rightarrow \mathrm{CBPQT}^{0}\right)$ of the cyclophane unit. ${ }^{21,16}$ In the case of a $20 \mathrm{~nm}$ thick ITO overlayer, the $\mathrm{CV}$ also exhibits two redox waves. However, the redox waves are shifted by about $90 \mathrm{mV}$ to more cathodic potentials and the second redox wave is irreversible. Indeed, we have shown previously that a minimal thickness $d_{\text {(ITO) }} \approx 60 \mathrm{~nm}$ is required to provide a good electrical contact. ${ }^{30}$ The irreversible redox behaviour observed for the reduction of $\mathrm{CBPQT}^{2+} \cdot \rightarrow \mathrm{CBPQT}^{0}$ may be due to the high resistivity of the ITO film.

The $\mathrm{CBPQT}^{4+}$ surface coverage $\Gamma$ can be estimated by integrating the cathodic peak area, for the first oxidation wave, according to $\Gamma=Q_{\mathrm{a}} / n F A$, where $F$ is the Faraday constant, $n$ the number or electrons exchanged $(n=2)$ and $A$ the surface area
(A)

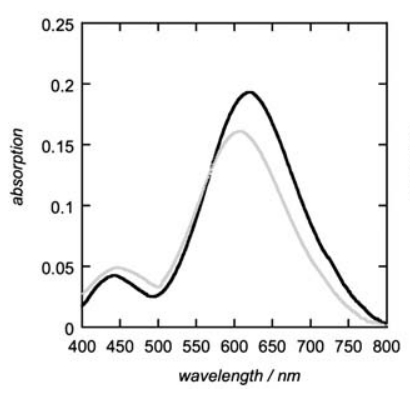

(B)

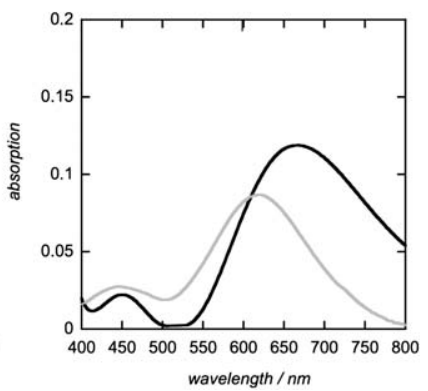

Fig. 8 UV/vis spectra of (A) ITO/Au NSs/ITO (20 nm) and (B) ITO/Au NSs/ITO $(240 \mathrm{~m})$ before (black line) and after modification with cyclophane (grey line) recorded in acetonitrile.
$\left(A=0.04 \mathrm{~cm}^{2}\right)$. A surface coverage $\Gamma=(1.64 \pm 0.9) \times 10^{13}$ molecules $\mathrm{cm}^{-2}$ was obtained. This is lower than the surface coverage obtained for ferrocene molecules grafted onto ITO using a similar click chemistry approach $\left(\Gamma=(5.16 \pm 0.9) \times 10^{14}\right.$ molecules $\left.\mathrm{cm}^{-2}\right){ }^{30}$ This might be due to the bulky nature of $\mathrm{CBPQT}^{4+}$ and the likely associated Coulombic repulsion between the cationic $\mathrm{CBPQT}^{4+}$ units attached to the surface.

Finally, UV/vis spectra of the $\mathrm{CBPQT}^{4+}$-modified ITO/Au NSs/ITO interfaces were recorded. Fig. 8 shows the absorption spectra of ITO/Au NSs/ITO interfaces coated with 20 and $240 \mathrm{~nm}$ ITO layers before and after grafting $\mathrm{CBPQT}^{4+}$ units. The plasmonic signal changes when $\mathrm{CBPQT}^{4+}$ is present on the interface showing in both cases a blue shift together with a decrease in the absorption intensity. The origin of the blue shift is currently not clear. However, it has been shown previously by us, that when ITO/Au NSs interfaces are coated with overlayers such as $\mathrm{SiO}_{x}$ having a refractive index of 1.48 (similar to that of an organic layer), a blue shift was observed. ${ }^{42}$ The $20 \mathrm{~nm}$ ITO overlayer shows better plasmonic signals and was used in the following experiments to demonstrate the formation of hostguest complexes with TTF.

\subsection{Formation of guest-host complexes}

TTF has proven to be a versatile redox-active system for the construction of switchable host-guest and interlocked systems. ${ }^{13}$ In particular, pseudorotaxanes prepared from electron-rich TTF units and the electron-deficient $\mathrm{CBPQT}^{4+}$ units have emerged as important systems for the construction of redox tunable assemblies (Fig. 9A). ${ }^{21,54-57}$ Here, we have exploited the faculty of TTF to form redox tunable complexes with $\mathrm{CBPQT}^{4+}$ as a means to specifically and reversibly modify a surface via complexation with surface-confined $\mathrm{CBPQT}^{4+}$ units. Fig. 9B shows the UV/vis spectra of the $\mathrm{CBPQT}^{4+}$ modified ITO/Au NSs/ITO $(20 \mathrm{~nm})$ interface before and after immersion of the interface in a TTF solution for $20 \mathrm{~min}$. The addition of the TTF results in the appearance of a characteristic absorption band consistent with the formation of a TTF-CBPQT ${ }^{4+}$ host-guest complex (see Fig. S2 in the ESI $\uparrow$ for the UV/vis spectra of $\mathrm{CBPQT}^{4+}$ and TTF$\mathrm{CBPQT}^{4+}$ host-guest complex recorded in acetonitrile solution). In particular, upon the addition of TTF, a broad absorption band centered around $\lambda=875 \mathrm{~nm}$ is observed, which is a diagnostic of the formation of a TTF-CBPQT ${ }^{4+}$ pseudorotaxane-like system. ${ }^{54}$ In addition, a significant red shift of $\approx 22 \mathrm{~nm}$ in the LSPR peak position is observed. This observation correlates with the increase in the refractive index of the surrounding area. ${ }^{56}$ To further prove the ability of the new interface containing surfacelinked $\mathrm{CBPQT}^{4+}$ to bind TTF, the $\mathrm{CV}$ of the $\mathrm{CBPQT}^{4+}$ modified ITO/Au NSs/ITO $(20 \mathrm{~nm})$ upon the addition of TTF was recorded (Fig. S3 in the ESI $\dagger$ ). The $\mathrm{CV}$ indicates that the first reduction wave of the $\mathrm{CBPQT}^{4+}$ unit is shifted by about $-20 \mathrm{mV}$ upon addition of TTF, presumably due to donor-acceptor interactions resulting from complex formation. Similar small shifts were reported by Stoddart et al. ${ }^{5}$

We next turned our attention to whether the surface-bound complexes could be disrupted by oxidizing the TTF unit with $\mathrm{Fe}\left(\mathrm{ClO}_{4}\right)_{3} \cdot{ }^{58,59}$ Chemical oxidation of TTF was carried out by immersion of the TTF-complexed interface into $\mathrm{Fe}\left(\mathrm{ClO}_{4}\right)_{3}(1$ $\mathrm{mM}$ ) in acetonitrile for $20 \mathrm{~min}$. The recorded UV/Vis spectrum 
(A)

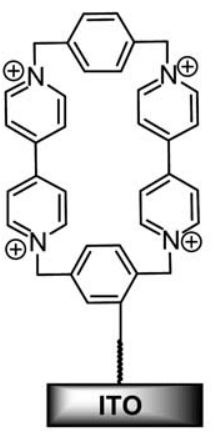

(I)

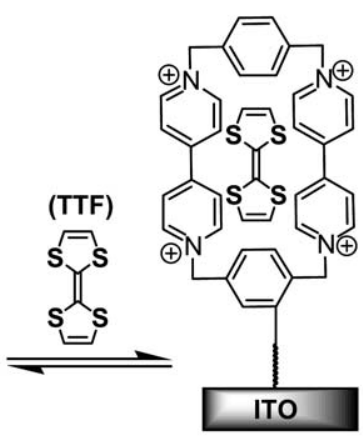

(II)

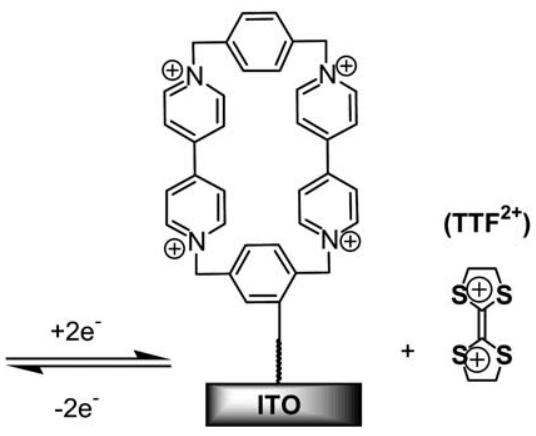

(III)
(B)

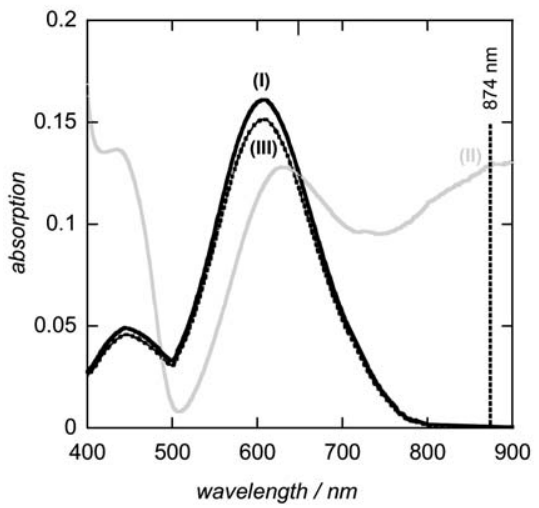

(C)

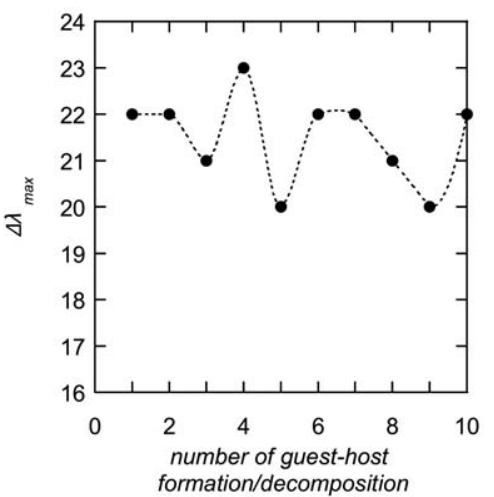

Fig. 9 (A) Schematic illustration of the interaction of surface-linked cyclophane host with TTF guest molecule before and after oxidation of the TTF unit. (B) UV/vis of $\mathrm{CBPQT}^{4+}$ modified ITO/Au NSs/ITO $(20 \mathrm{~nm}$ ) interfaces in acetonitrile: (I) before, (II) after addition of TTF and (III) after chemical oxidation of TTF, (C) change of $\lambda_{\max }$ during several complexation/decomplexation cycles of $\mathrm{CBPQT}^{4+} / \mathrm{TTF}$ complex.

shows a blue shift of the LSPR peak, due to the decrease in the refractive index of the surrounding area. ${ }^{56}$ Indeed, the initial LSPR position is obtained, thereby suggesting the dethreading of the TTF unit from the $\mathrm{CBPQT}^{4+}$ unit, presumably due to electrostatic repulsion of the $\mathrm{CBPQT}^{4+}$ ring and the oxidized TTF unit. In addition, no signal due to the host-guest complex at $\lambda=856 \mathrm{~nm}$ is observed, which is a good indication that TTF unit is no longer bound to the cyclophane and that the plasmonic properties of the ITO/Au NSs/ITO interface can be modified by complexation of the $\mathrm{CBPQT}^{4+}$ species. Indeed, formation and disruption of the TTF-CBPQT ${ }^{4+}$ complex using $\mathrm{Fe}\left(\mathrm{ClO}_{4}\right)_{3}$ can be performed several times without degradation of the LSPR signal and significant change in the LSPR shift (Fig. 9C).

\section{Conclusion}

The use of click chemistry to covalently link alkyne-functionalized $\pi$-electron deficient $\mathrm{CBPQT}^{4+}$ to ITO/Au NSs/ITO interfaces has been demonstrated. The presence of surface-linked $\mathrm{CBPQT}^{4+}$ was shown by XPS, CV and UV/vis measurements. The interfaces were used to demonstrate the possibility of recording the formation and dethreading of guest-host complexes using the LSPR. The capture and release of guest molecules can potentially be used to program LSPR interfaces to selectively capture and release specific species (e.g. TTF functionalized biomolecules) from a complex mixture. The applications of such "tunable" plasmonic interfaces are thus broad. In addition, besides LSPR other sensing techniques such as Quartz microbalance (QCM) transducers ${ }^{60}$ will make possible such type of investigations enlarging the scope of the developed surface chemistry.

\section{Acknowledgements}

The EU-FEDER and Interreg IV (project "Plasmobio"), the Centre National de la Recherche Scientifique (CNRS) and the Nord-Pas-de Calais region are gratefully acknowledged for financial support. P. W. thanks the Agence Nationale de la Recherche (ANR-09-JCJC-0032-01) for funding.

\section{References}

1 E. R. Kay, D. A. Leigh and F. Zerbetto, Angew. Chem., Int. Ed., 2007, 46, 72 .

2 M. J. Blanco, J. C. Chambron, M. C. Jiménez and J. P. Sauvage, Top. Stereochem., 2003, 23, 125.

3 D. H. Busch, Top. Curr. Chem., 2005, 249, 1.

4 M. A. Olson, Y. Y. Botros and J. F. Stoddart, Pure Appl. Chem., 2010, 82, 1569.

5 P. L. Anelli, P. R. Ashton, R. Ballardini, V. Balzani, M. Delgado, M. T. Gandolfi, T. T. Goodnow, A. E. Kaifer, D. Philp, M. Pietraszkiewicz, L. Prodi, M. V. Reddington, M. V. Slawin, 
A. M. Z. Spencer, J. F. Stoddart, C. Vicent and D. J. Williams, J. Am. Chem. Soc., 1992, 114, 193

6 J. J. Davis, G. A. Orlowski, H. Rahman and P. D. Beer, Chem Commun., 2010, 46, 54.

7 T. Lu, L. Zhang, G. W. Gokel and A. E. Kaifer, J. Am. Chem. Soc., 1993, 115, 2542.

8 A. B. Braunschweiger, B. H. Northrop and J. Fraser Stoddart, J. Mater. Chem., 2006, 16, 32.

9 T. D. Nguyen, I. Liu, S. Saha, K. C.-F. Leung, J. F. Stoddart and J. I. Zink, J. Am. Chem. Soc., 2007, 129, 626.

10 T. Nguyen, H.-R. Tseng, P. C. Elestre, A. H. Flood, Y. Liu, J. I. Zink and J. F. Stoddart, Proc. Natl. Acad. Sci. U. S. A., 2005, 102, 10029.

11 A. S. Kumar, S. Saha, T. Takami, T. J. Huang, J. F. Stoddart and P. S. Weiss, ACS Nano, 2010, 4, 3697.

12 A. Coskun, P. J. Wesson, R. Klajn, A. Trabolsi, L. Fang, M. A. Olson, S. K. Dey, B. A. Grzybowski and J. F. Stoddart, J. Am. Chem. Soc., 2010, 132, 4310.

13 R. Klajn, L. Fang, A. Coskun, M. A. Olson, P. J. Wesson, J. F. Stoddart and B. A. Grzybowski, J. Am. Chem. Soc., 2009, 131, 4233.

14 B. K. Juluri, A. S. Kumar, Y. Liu, T. Ye, Y.-W. Yang, A. H. Flood, L. Fang, J. F. Stoddart, P. S. Weiss and T. J. Huang, ACS Nano, 2009, 3, 291.

15 Y. Liu, A. H. Flood, P. A. Bonvallet, S. A. Vignon, B. Northrop, H.R. Tseng, J. Jeppesen, T. J. Huang, B. Brough, M. Baller, S. Magonov, S. Solares, W. A. Goddard, C.-M. Ho and J. F. Stoddart, J. Am. Chem. Soc., 2005, 127, 9745-9759.

16 G. Cooke, L. M. Daniels, F. Cazier, J. F. Garety, S. G. Hewage, A. Parkin, G. Rabani, V. M. Rotello, C. C. Wilson and P. Woisel, Tetrahedron, 2007, 63, 11114.

17 G. Cooke, J. F. Garety, S. Marbruk, G. Rabani, V. M. Rotello, G. Surpateanu and P. Woisel, TetrahedronLett., 2006, 47, 783.

18 T. Ikeda, M. Higuchi and D. G. Kurth, J. Am. Chem. Soc., 2009, 131, 9158.

19 D. L. Simone and T. M. Swager, J. Am. Chem. Soc., 2000, 122, 9300.

20 G. Cooke, J. F. Garety, S. Marbruk, G. Rabani, V. M. Rotello, G. Surpateanu and P. Woisel, Tetrahedron Lett., 2006, 47, 783.

21 B. C. Bunker, D. L. Huber, J. G. Kushmerick, T. Dunbar, M. Kelly, C. Matzke, J. Cao, J. O. Jeppesen, J. Perkins, A. H. Flood and J. F. Stoddart, Langmuir, 2007, 23, 31.

22 H. Nandivada, X. Jiang and J. Lahann, Adv. Mater., 2007, 19, 2197.

23 H. C. Kolb, M. G. Finn and K. B. Sharpless, Angew. Chem., Int. Ed., 2001, 40, 2004

24 M. Bria, J. Bigot, G. Cook, J. Lyskawa, G. Rabani, V. M. Rotello and P. Woisel, Tetrahedron, 2009, 1, 400.

25 O. S. Miljanic, W. R. Dichtel, S. Mortezaei and J. F. Stoddart, Org. Lett., 2006, 8, 4835.

26 J. M. Spruell, W. R. Dichtel, J. R. Heath and J. F. Stoddart, Chem.Eur. J., 2008, 14, 4168

27 J. N. Anker, W. Paige Hall, O. Lyandres, N. C. Shah, J. Zhao and R. P. Van Duyne, Nat. Mater., 2008, 7, 442

28 E. M. Larsson, J. Alegret, M. Kall and D. S. Sutherland, Nano Lett., 2007, 7, 1256

29 G. Kalyushny, A. Vaskevich, M. A. Schneeweiss and I. Rubinstein, Chem.-Eur. J., 2002, 8, 3850.

30 J. Niedziólka-Jönsson, F. Barka, X. Castel, M. Pisarek, N. Bezzi, R. Boukherroub and S. Szunerits, Langmuir, 2010, 26, 4266.

31 M. D. Malinsky, K. L. Kelly, G. C. Schatz and R. P. Van Duyne, J. Am. Chem. Soc., 2001, 123, 1471.

32 Y. Luo, J. Ruff, R. Ray, Y. L. Gu, H. J. Ploehn and W. A. Scrivens, Chem. Mater., 2005, 17, 5014.

33 S. Szunerits, M. R. Das and R. Boukherroub, J. Phys. Chem. C, 2008, 12,8239 .
34 S. Szunerits, S. Ghodbane, J. Niedziolka-Jonsson, E. Galopin, F. Klausner, A. Akjouj, Y. Pennec, B. Djafari-Rouhani, R. Boukherroub and D. Steinmuller-Nethel, J. Phys. Chem. C, 2010, 114, 3346.

35 E. Galopin, A. Noual, J. Niedziólka-Jönsson, M. JönssonNiedziólka, A. Akjouj, Y. Pennec, B. Djafari-Rouhani, R. Boukherroub and S. Szunerits, J. Phys. Chem. C, 2009, 113, 15921.

36 E. Galopin, L. Touahir, J. Niedziólka-Jönsson, R. Boukherroub, A. C. Gouget-Laemmel, J.-N. Chazalviel, F. Ozanam and S. Szunerits, Biosens. Bioelectron., 2010, 25, 1199.

37 I. Doron-Mor, Z. Barkay, N. Filip-Granit, A. Vaskevich and I. Rubinstein, Chem. Mater., 2004, 16, 3476.

38 T. Okamoto, I. Yamaguchi and T. Kobayashi, Opt. Lett., 2000, 25, 372.

39 I. Ruach-Nir, T. A. Bendikov, I. Doron-Mor, Z. Barkay, A. Vaskevich and I. Rubinstein, J. Am. Chem. Soc., 2007, 129, 84.

40 S. Gao, N. Koshizaki, E. Koyama, H. Tokushisa, T. Sasaki, J.K. Kim, Y. Cho, D.-S. Kim and Y. Shimizu, Anal. Chem., 2009, 81, 7703.

41 A. V. Whitney, J. W. Elam, S. Zou, A. V. Zinovev, P. C. Stair, G. C. Schatz and R. P. Van Duyne, J. Phys. Chem. B, 2005, 109, 20522.

42 S. Szunerits, V. G. Praig, M. Manesse and R. Boukherroub, Nanotechnology, 2008, 19, 195712.

43 X. Castel, R. Boukherroub and S. Szunerits, J. Phys. Chem. C, 2008, 112, 15813.

44 X. Castel, R. Boukherroub and S. Szunerits, J. Phys. Chem. C, 2008, 112, 10883.

45 S. Szunerits, Y. Coffinier, S. Janel and R. Boukherroub, Langmuir, 2006, 22, 10716.

46 K. S. Yee, IEEE Trans. Antennas Propag., 1966, 14, 302.

47 A. Taflove, Computational Electrodynamics: The Finite-Difference Time-Domain Method, Artech House, Norwood, MA, 1995.

48 J. P. Berenger, J. Comput. Phys., 1994, 114, 185.

49 E. Galopin, J. Niedziółka-Jönsson, A. Akjouj, Y. Pennec, B. DjafariRouhani, A. Noual, R. Boukherroub and S. Szunerits, J. Phys. Chem. $C, 2010,114,11769$.

50 M. Manesse, V. Stambouli, R. Boukherroub and S. Szunerits, Analyst, 2008, 133, 1097-1103.

51 F. Zhang and M. P. Srinivasan, Langmuir, 2004, 20, 2309.

52 J. Huang, H.-R. Tseng, L. Sha, W. Lu, B. Brough, A. H. Flood, B.D. Yu, P. C. Celestre, J. P. Chang, J. F. Stoddart and C.-M. Ho, Nano Lett., 2004, 4, 2065.

53 K. J. McKenzie, J. Niedziolka, C. A. Paddon, F. Marken, E. Rozniecka and M. Opallo, Analyst, 2004, 129, 1181.

54 G. Cooke, J. F. Garety, S. G. Hewage, G. Rabani, V. M. Rotello and P. Woisel, Chem. Commun., 2006, 4119.

55 M. Bria, G. Cooke, A. Cooper, J. F. Garety, S. G. Hewage, M. Nutley, G. Rabani and P. Woisel, Tetrahedron Lett., 2007, 48, 301.

56 Y. B. Zheng, Y.-W. Yang, L. Jensen, L. Fang, B. K. Juluri, A. H. Flood, P. S. Weiss, J. F. Stoddart and T. J. Huang, Nano Lett., 2009, 9, 819.

57 J. M. Spruell, W. F. Paxton, J.-C. Olsen, D. Benitez, E. Tkatchouk, C. L. Stern, A. Trabolsi, D. C. Friedman, W. A. Goddard and J. F. Stoddart, J. Am. Chem. Soc., 2009, 131, 11571-11580.

58 J. Bigot, B. Charleux, G. Cooke, F. Delattre, D. Fournier, J. Lyskawa, L. Sambe, F. Stoffelbach and P. Woisel, J. Am. Chem. Soc., 2010, 132, 10796.

59 Y.-L. Zhao, W. R. Dichtel, A. Trabolsi, S. Saha, I. Aprahamian and J. F. Stoddart, J. Am. Chem. Soc., 2008, 130, 11294.

60 F. L. Dickert, A. Haunschild and V. Maune, Sens. Actuators, B, 1993, 12, 169 . 